\title{
DESPLAZAMIENTOS, TRANSFORMACIONES Y RETOS DE UNA EDUCACIÓN FILOSÓFICA EN UNA SOCIEDAD DEMOCRÁTICA: REFLEXIONES EN TORNO A UN VIEJO CUADERNO DE FILOSOFÍA
}

\author{
Diego Antonio Pineda Rivera* \\ doi:10.11144/Javeriana.uph34-69.dtrf
}

\section{RESUMEN}

En el presente artículo, el autor reflexiona en torno al pasado, presente y futuro de una educación filosófica en el marco de un modo de vida democrático integrando tres niveles distintos: uno autobiográfico (allí la reflexión se suscita por la visión del cuaderno escolar de filosofía del padre del autor), otro conceptual (en donde se retoma la concepción pragmatista de la filosofía de John Dewey) y un tercero descriptivo y propositivo (en el cual se analiza lo que ha ocurrido en los últimos años con la enseñanza filosófica y se hace la propuesta de una educación filosófica consecuente

* Pontificia Universidad Javeriana, Bogotá, Colombia.

Correo electrónico: diegopi@javeriana.edu.co

Para citar este artículo: Pineda Rivera, D.A. (2017). Desplazamientos, transformaciones y retos de una educación filosófica en una sociedad democrática: reflexiones en torno a un viejo cuaderno de filosofía. Universitas Philosophica, 34(69), pp. 13-51. ISSN 0120-5323, ISSN en línea 23462426. doi:10.11144/Javeriana.uph34-69.dtrf

Una versión preliminar de este escrito fue presentada primero como una conferencia oral y luego como un texto escrito en el Segundo Foro Internacional. La filosofía en la educación media superior: formación docente y ciudadanía democrática, organizado por la Subsecretaría de Educación Media Superior de la Secretaría de Educación Pública de México en septiembre de 2012. La conferencia original se puede seguir a través de YouTube bajo el título "La enseñanza de la filosofía en una sociedad democrática”. El texto está disponible en: http://www.sems.gob.mx/work/models/sems/ cssCSSEMS/Anexo_11Foro2memorias.pdf 
con tales desarrollos). Se trata de poner de presente, sobre todo, los diversos desplazamientos y transformaciones que ha sufrido la enseñanza filosófica en el último siglo a través del contraste entre las viejas prácticas de una filosofía centrada en dar una "visión correcta del mundo" y las exigencias de una filosofía que cumpla una función crítica de la sociedad y el conocimiento, retomando con ello el ideal deweyano de que la filosofía cumpla con una función a la vez crítica y reconstructiva de la experiencia presente. Concluye el artículo proponiendo diez retos para la educación filosófica del futuro.

Palabras clave: educación filosófica; democracia; John Dewey; enseñanza de la filosofía 


\title{
DISPLACEMENTS, TRANSFORMATIONS AND CHALLENGES OF PHILOSOPHICAL EDUCATION IN A DEMOCRATIC SOCIETY: REFLECTIONS UPON AN OLD PHILOSOPHY NOTEBOOK
}

\author{
Diego Antonio Pineda Rivera
}

\begin{abstract}
In this paper the author reflects upon the past, the present and the future of philosophical education within the framework of a democratic mode of living, integrating three levels of argumentation: an autobiographic level, triggered by the encounter with an old school notebook that belonged to the author's father; a conceptual level, in which the author recalls John Dewey's pragmatist approach to philosophy; and a descriptive and proactive level, in which the author examines recent developments concerning the teaching of philosophy and proposes a perspective on philosophical education in tune with these. The author underscores the importance of different displacements and transformations undergone by the practice of teaching philosophy during the last century, and sets up a contrast between the old practices, intended to provide a "correct view of the world", and the urge for philosophy to provide a critique of society and knowledge. In this way, the author draws on Dewey's ideal, according to which
\end{abstract}


philosophy should carry out both a critique and a reconstruction of present experience. Finally, the author sets forth ten challenges for future philosophical education.

Key words: philosophical education; democracy; John Dewey; teaching philosophy 
Asipues, la sabiduria (sophia) fue llamada, así como si fuera una cierta claridad (sápheia), en tanto que clarifica todas las cosas. Esta condición de lo claro (saphés), al ser algo luminoso (phaés), recibe su denominación de la luz y la luminosidad (pháos, phós), por traer a la luz (phós) las cosas que están ocultas.

Filópono (Ross, 8b). En Aristóteles. Fragmentos.

Pues bien, es forzoso, creo yo, que, si la naturaleza filosófica que definiamos obtiene una educación adecuada, se desarrolle hasta alcanzar todo género de virtudes; pero, si es sembrada, arraiga y crece en lugar no adecuado, llegará a todo lo contrario, si no ocurre que alguno de los dioses le ayude.

Platón. La República, 492a.

\section{Un encuentro inesperado}

HAY OBJETOS QUE a primera vista son insignificantes, casi despreciables, pero que, cuando se descubren de repente y en el momento apropiado, cobran un valor y un significado infinitos. Supongo que ello es lo que ocurre cuando un antropólogo o un arqueólogo descubren un viejo trozo de cerámica en medio de unas ruinas de hace muchos siglos: aparentemente no es más que un guijarro cualquiera; sin embargo, en cuanto se le interpreta a la luz de nuevos fragmentos y con base en un saber previamente consolidado, ese guijarro cualquiera se transforma, como por arte de magia, en algo que nos habla de una cultura a la que nos sentimos vinculados y enriquece nuestra comprensión sobre el lugar que nos corresponde en este mundo. Ya no será, entonces, un simple trozo de cerámica: ahora será el símbolo de lo que hemos sido y seguiremos siendo; y el testimonio de que no hemos llegado al mundo venidos de un asteroide cualquiera, sino que somos seres arraigados en una cultura y en una historia que, aunque desconozcamos en muchos aspectos, es tan nuestra como los utensilios con que comemos, los vehículos en que nos desplazamos o los libros que leemos.

Hace unos pocos años, casi por casualidad, descubrí un objeto que ignoraba me perteneciera y cuya simple existencia me era por completo desconocida. Me llegó de la forma más inesperada: mi esposa, en medio de la mudanza de una casa 
que habíamos habitado por casi treinta años, me lo entregó preguntándome si podía botarlo. En principio le dije que sí: era algo de lo que desconocía su existencia y su valor: un viejo cuaderno, un cuaderno cualquiera que en principio no me traía recuerdo alguno y por el que no tenía por qué sentir ningún aprecio. Antes de desecharlo, tuve, sin embargo, una cierta curiosidad por revisar su contenido: se trataba del cuaderno de filosofía de mi padre cuando era un estudiante de secundaria. Para mí, una persona dedicada por tantos años a la enseñanza de la filosofía, se trataba al menos de un objeto curioso; y el hecho de que fuera el cuaderno escolar de filosofía de mi propio padre le otorgaba al menos un valor afectivo. Ignoro cómo llegó dicho objeto a mi casa: supongo que entre los papeles que me entregó mi madre a la muerte de él, que siempre me llamó su secretario. Era extraño, sin embargo: me acuerdo de haber revisado uno a uno los documentos que me fueron entregados a los pocos días de su muerte y no recuerdo haber visto nunca ese viejo cuaderno.

Como objeto es algo más bien común: un cuadernito de apenas $16 \times 24 \mathrm{~cm}$, de alrededor de 90 páginas, ya un poco amarillas, aunque bastante bien conservadas; la tapa, en cartulina de la época, a pesar de algunas manchas, se conservaba también en buen estado. Mi padre nació en 1912 y debió hacer sus últimos cursos de secundaria hacia finales de los años veinte o comienzos de los años treinta del siglo pasado; según esto, ese cuaderno debe tener, si estaba concluyendo sus estudios secundarios hacia los diecisiete o dieciocho años, ya casi nueve décadas.

Lo más destacable era, sin duda, que estaba escrito en la inconfundible letra de mi padre. Sorprendente, sin embargo, era que se trataba precisamente de su cuaderno de filosofía y que había llegado inesperadamente a mis manos después de muchos años de estar oculto, como si hubiese en ello un destino prefijado. Si hubiera llegado a manos de alguno de mis otros hermanos (abogados, ingenieros) es muy probable que lo hubieran desechado o que, en el mejor de los casos, me lo hiciesen llegar como una rara curiosidad. Sin embargo, había llegado a mis manos y no en un momento cualquiera: preparaba por entonces una conferencia sobre la enseñanza de la filosofía en el bachillerato y los desplazamientos y transformaciones que esta había tenido en los últimos años, que debía presentar en México unos días después. Inmediatamente lo que venía preparando adquirió una nueva luz, pues había hallado, casi sin quererlo, un medio de contraste interesante para mis propias ideas sobre el tema que me ocupaba. Había allí un modo 
de enseñar filosofía, una concepción de esta, de su aprendizaje y de su enseñanza, que, si bien no era el que estaba buscando, me ofrecía una perspectiva nueva desde la cual juzgar las cosas.

Lo leí con avidez. Lo primero que me sorprendió, antes incluso de explorar su contenido, era el hecho de que se trataba de un cuaderno, es decir, de un texto escrito a mano en donde se registraba paso a paso el devenir de una enseñanza. No era como los cuadernos de ahora, que solo son libretas de apuntes. Los estudiantes de hoy toman notas más bien al azar, pero casi nunca llevan en sentido estricto un cuaderno, pues un cuaderno es algo que se construye bajo la guía estricta de un maestro que transmite ordenadamente una materia para que sea aprendida por sus estudiantes. En un auténtico cuaderno no hay tanto los apuntes de clase de un alumno como la exposición ordenada de un saber por parte de un maestro. Es el maestro el que escribe -con la transmisión de su doctrina y a través de la pluma del alumno- el cuaderno, es en él donde queda registrado el testimonio de su enseñanza. Un cuaderno es una forma particular de hacer saber a otros, de hacer circular el saber, de transmitir una enseñanza, de provocar un cierto tipo de aprendizaje. Y en un cuaderno de filosofía quedan marcadas las señas de una concepción de la filosofía y de una práctica pedagógica en filosofía.

También resultaba sorprendente el estricto orden en que se llevaba el cuaderno. No se trataba, ya lo dije, de notas tomadas al azar, sino de la exposición sistemática de un saber que se podía seguir paso a paso, sin que en ella hubiese vacíos o saltos fundamentales. No tenía un índice, pero tampoco lo necesitaba: la exposición era tan coherente, los títulos y subtítulos tan precisos, el orden de exposición de los conceptos tan claramente elaborado que no había ocasión para perderse en su lectura. Era un texto ordenado y construido con una intención. Se podrían recorrer sus casi noventa páginas sin perder nunca de vista el conjunto que daba sentido a cada parte. Pero, ¿qué nos deparaba su lectura?, ¿qué tenía para enseñarnos ese viejo cuaderno de filosofía?, ¿qué nos podría decir de lo que significa enseñar filosofía hoy?

\section{Lo que nos puede mostrar un viejo cuaderno de filosofía}

Planteémoslo de otra forma: ¿qué era lo que había que ver en ese viejo cuaderno?, ¿cómo había que mirarlo? Por supuesto, se trataba de leerlo. Pero, 
¿para qué? ¿Qué podía buscar o encontrar allí ? Ante todo, pensé inmediatamente, era preciso deshacerse de prejuicios para poderlo examinar mejor. Era necesario despojarse de toda mirada afectiva -pues, aun siendo el cuaderno de mi padre, no era más que un espécimen, una muestra de algo más fundamental: de una intención filosófica y pedagógica, de una enseñanza que se desplegaba ante mis ojos-; y era preciso también evitar juzgarlo, cosa fácil, como un modo trasnochado y viejo de enseñar, de transmitir un saber, un modelo de esa educación tradicional sobre las ruinas de la cual todos los que somos educadores construimos nuestros discursos pedagógicos. Lo que había allí no era más que eso: un viejo cuaderno de filosofía. Pero, pasado el espasmo del descubrimiento, era preciso ir más allá, hacia lo que nos podía revelar, hacia la idea de filosofía que lo informaba, hacia el intento que allí se hacía por desplegar un saber. Pero, ¿qué saber ?, ¿y cómo se constituía ese saber a través de un ejercicio de enseñanza?

Lo primero que captó mi atención fue el hecho de que allí la filosofía se enseña como una doctrina, como una especie de catecismo cuyas respuestas deben ser aprendidas con precisión, como un saber cerrado, e incluso como una "visión del mundo correcta" que debe ser enteramente aprehendida y acatada. Y pongo entre comillas la expresión "visión del mundo correcta" porque lo que pretendo subrayar es que, por aquellos tiempos, cuando a alguien se le enseñaba filosofía, se le pretendía decir qué era lo que debia creer y qué era lo que debía saber, pues eso era precisamente lo que era correcto saber y creer. No se trataba, entonces, de enseñar y de aprender cualquier cosa, sino de obtener un saber que debería quedar escrito en el alma con tinta indeleble. La filosofía no debía ser un saber cualquiera, de esos que se aprenden para luego aplicar, o simplemente para olvidar, si no se le encontrara alguna utilidad. Era el ideal tantas veces mentado de una "filosofía perenne".

Por ello mismo, y como consecuencia necesaria de lo anterior, la filosofía (es decir, la doctrina, la visión del mundo) se debia aprender tal cual era enseñada, es decir, sin que diera lugar a dudas, objeciones o controversias. No debía haber, pues, ninguna diferencia entre lo que el profesor enseñaba y lo que el alumno debía aprender. Comenio (1998), el gran pedagogo checo y el gran gestor de la institución escolar moderna, decía que en la escuela se trata de "enseñar todo a todos y totalmente". Y "totalmente" quería decir precisamente esto: que lo que se enseña, y lo que se aprende, debe ser enseñado y aprendido sin que haya lugar a dudas, a vacilaciones, a objeciones, a preguntas... y, mucho menos, a discusión. 
En el cuaderno de mi padre se cumplió plenamente el ideal pedagógico de Comenio: allí, en ese viejo cuaderno, está todo lo que es preciso saber de filosofía para estar a salvo del error y de las doctrinas que pudiesen oscurecer el intelecto o la voluntad. Lo que es perenne debe ser enseñado y debe ser aprendido, como una totalidad indiferenciada.

También la filosofía, como las demás disciplinas, se debía aprender tal cual era enseñada, sin que hubiera lugar para la duda, la objeción o la controversia. La doctrina, entonces, era preciso que se aprendiera "al dictado", pues era esta la manera de garantizar que las cosas se aprendieran tal cual eran enseñadas. No de otra forma se entiende el modo como está redactado este cuaderno: como ya dije, no se trata de "apuntes de clase"; no, este cuaderno es una especie de tratado en donde las ideas se van exponiendo de forma ordenada y sistemática, hasta constituirse en un cuerpo de doctrina. Como lo veremos a continuación, cuando cite algunos pasajes del viejo cuaderno, lo que hay allí es un plan de enseñanza organizado sistemáticamente, pues el profesor dictaba, los alumnos copiaban, el profesor hacía aclaraciones orales y los alumnos daban cuenta de lo aprendido (que, por principio, debía coincidir con lo enseñado) en los exámenes. Tal vez se aceptaba alguna pregunta aclaratoria, pero nadie podía objetar lo que se enseñaba, porque se enseñaba como algo totalizante, como una visión del mundo correcta no cuestionable. Que fuera "al dictado" era, entonces, la manera de garantizar que no hubiera diferencia entre lo enseñado y lo aprendido.

La enseñanza estaba, por supuesto, totalmente centrada en el profesor, pues él presentaba la doctrina y él mismo hacia la crítica que, de acuerdo con los fines de una enseñanza que se concebía a sí misma como totalizante, se consideraba "correcta”. El alumno, tal vez, podía pedir explicaciones, pero no hacer críticas. El profesor presentaba las ideas, la doctrina; y, por supuesto, si de la doctrina había que hacer una crítica, era a él, al maestro, a quien correspondía hacerla, pues él era quien sabía qué era correcto pensar y qué no era correcto pensar. La crítica ni podía ni debía hacerla el alumno, pues a él solo le correspondía aprender lo enseñado.

Citaré a continuación dos pequeños pasajes de este cuaderno que he transcrito para ilustrar mejor lo que acabo de indicar. El primero de ellos es un pasaje de las páginas 13 y 14 que se llama "La belleza". Es un pasaje corto, pero bastante representativo de lo que constituía ese tipo de práctica de enseñanza de la filosofía. Dice así: 


\section{La belleza}

Se da el nombre de belleza a la resultante de las tres propiedades metafísicas del ser; todo ser es bello en proporción de su unidad, verdad y bondad.

Se ha definido la belleza como "aquello cuya aprehensión agrada" o bien como "esplendor de un ideal de perfección".

La belleza tiene íntimas relaciones con las tres propiedades del ser, pero no se confunde con ninguna de ellas; así:

La unidad permite distinguir cada ser de sus semejantes, da orden y proporción al conjunto; es indispensable para que exista la belleza y, sin embargo, es incapaz de producirla por sí sola, ya que no se dirá nunca que una unidad en abstracto es bella.

La verdad es también indispensable para la belleza, ya que a esta no se la puede concebir sin una realidad objetiva, o al menos sin la realización subjetiva de un ser posible; tanto es así que las mismas ficciones de la imaginación solo adquieren belleza en razón de su verosimilitud; pero es por sí sola tan incapaz de producir la belleza por sí misma como la anterior; y no se podría decir que una verdad matemática o metafísica es bella.

La bondad no es menos necesaria para constituir la belleza. El mal es un concepto negativo y, por lo tanto, la belleza no podría proceder de él; por lo tanto, un ser será bello tan solo en la proporción en que refleje las perfecciones divinas, e indirectamente en razón de la conveniencia de las condiciones del ser a su naturaleza o al orden del mundo.

Eso era lo que copiaba y aprendía al dictado un alumno de filosofía hace ya casi noventa años. Quiero advertir algunas cosas que son interesantes. Lo primero es la gran coherencia. La escritura es perfecta, la precisión de los conceptos admirable, el orden en que se presentan absolutamente consistente. Este pasaje, que se refiere al concepto de belleza, no se presenta como algo gratuito, sino como el resultado de una exposición previa de las llamadas "propiedades trascendentales del ser" (unidad, verdad y bondad), que previamente se han explicado en las páginas 9 a 12. La belleza se nos ofrece, entonces, como "la resultante de las tres propiedades metafísicas del ser”, pero sin que se confunda con ninguna de ellas.

Aquí todo se ajusta a un orden. Se trata de una exposición sistemática, organizada. Pero lo que busca este estilo de enseñanza es fijar conceptos a través de definiciones y de explicaciones precisas. Aquí no hay nada qué explorar, ni qué discutir. Se trata de delimitar lo que debe ser pensado y el modo como debe ser 
pensado. Aquí no hay ni preguntas para explorar lo aprendido, ni discusiones sobre el significado de las proposiciones en juego; tampoco hay ejercicios que permitan explorar el significado de los conceptos; y, sobre todo, no se permite que la gente disienta. No se trata de pensar o de generar nuevas ideas, o de tener perspectivas distintas sobre un mismo asunto. Se trata, ya lo decíamos, de aprender lo enseñado: de eso... y de nada más.

Examinemos ahora un segundo pasaje: se llama "El panteísmo". Tiene dos partes, primero la exposición y luego la crítica, que presentaré por separado. Dice así:

\section{El panteísmo (exposición)}

El Panteísmo idealista es muy antiguo, [...] fue renovado en los tiempos modernos por Baruch Espinoza y, más recientemente, por Hegel.

Para Espinoza, Dios constituye la realidad del universo; posee dos perfecciones esenciales: la extensión y el pensamiento, los cuales aparecen de modo transitorio y mutable en los seres que componen el mundo. Para Espinoza no hay diferencia esencial entre Dios y el mundo y es imposible concebirlo el uno sin el otro; y Dios es el mundo mismo en su naturaleza y en sus propiedades. El mundo es la manifestación transitoria y finita de este mismo Dios. Hegel presenta esta misma teoría de modo muy oscuro y contradictorio; para él, existe la evolución necesaria y eterna del absoluto, que no es sino un constante progreso; [...] De modo que todo ser llega a la existencia por esta triple fase [tesis-antítesis-síntesis] y toda síntesis es el punto de partida de nuevas oposiciones, distinciones e identificaciones, de lo cual resulta un progreso constante e indefinido.

Lo más destacable, sin embargo, es que por aquel entonces no se leía directamente a los filósofos en una clase de filosofía (o, si se lo hacía, era de un modo totalmente ocasional). Es muy posible que ni los mismos maestros hubiesen leído directamente a los filósofos; seguramente solo leían lo que los manuales decían de los filósofos. Había ya, pues, un modo prefijado de exponer una filosofía, sea bajo la forma de lo que decía un autor o bajo la forma de un problema filosófico y, por tanto, había una sola forma posible de aprenderlo.

No había un trato de primera mano con los filósofos; y, de esta manera, el conocimiento filosófico no era más que un conocimiento de segunda, o incluso de tercera mano -lo que pensaba el filósofo era traducido por el autor del manual, de donde lo tomaba el maestro y lo transmitía al alumno-. Allí, al menos 
en la enseñanza de la educación media, nadie leía directamente al autor, pues lo que se tenía que aprender era lo que había en el cuaderno, que era a su vez lo que dictaba el maestro. No es que las ideas se expusieran sin ningún tipo de crítica, pero la crítica no la hacía el alumno como parte de su propio aprendizaje, sino que también esta le correspondía al maestro, pues él era el encargado no solo de enseñar, sino de fijar la perspectiva correcta en que algo debía ser aprendido. Con esto en mente, veamos ahora la crítica del panteísmo.

\section{El panteísmo (crítica)}

Crítica: Sea cual fuere la forma adoptada por el panteísmo, la teoría resulta opuesta a la razón. No es posible admitir lucubraciones sin tener que inclinarse ante la identidad de los contrarios; así, Dios resulta a un tiempo necesario y contingente, perfecto e imperfecto, finito e infinito, simple y compuesto, inmutable y sujeto a cambios, sabio y desprovisto de inteligencia, inmenso y localizable, libre y privado de libertad, santo y criminal, dichoso y desgraciado. Todo ello, en resumen, equivale a decir que Dios no existe, ya que la inteligencia se resiste a admitir la divinidad en esta incoherente mescolanza de cualidades opuestas e incompatibles. Con razón dice Cousin: "El panteísmo no es sino un ateísmo disfrazado".

Se puede decir que el panteísmo resulta peor que el mismo ateísmo, ya que envilece el concepto de la divinidad hasta el punto de encerrar en él todo lo abyecto que se encuentra en la naturaleza. Desde el punto de vista moral, sus consecuencias son aún peores: si todo se confunde con la divinidad, no existe diferencia entre lo bueno y lo malo, lo bello y lo feo; hay identidad entre el superior y el inferior, y no hay ley posible; la noción de deber resulta un absurdo; en una palabra, el panteísmo destruye toda moral.

Está claro a qué está ordenada la crítica: a decir, con toda la claridad posible, en qué está errado aquello que se acaba de presentar (en este caso el panteísmo). Con ello, además, se busca dejar claro qué se debe creer y qué no; y por qué no se debe creer eso y a la luz de qué no se debe creer. Ya no solo se trata de fijar conceptos, se trata de fjar una perspectiva de mundo, una manera de ver el mundo, una visión correcta del mundo a la cual nada pueda oponerse; y se trata también de que el alumno sepa lo que debe creer y, sobre todo, de que se le ponga a salvo de ciertos errores doctrinales y morales, como el materialismo, el panteísmo, el ateísmo o el comunismo. Casi la mitad del cuaderno se ocupa de la refutación de estos errores doctrinales y morales. 
Esta pretensión de fijar una manera de ver el mundo, por supuesto, estaba al servicio de otros intereses, fundamentalmente intereses de orden político y religioso. Desde luego, se trata del cuaderno de un alumno de un colegio de una institución católica de los años veinte o treinta del siglo anterior; y allí se hacía de la filosofía como en aquel tiempo se la entendía, una herramienta para evitar que los alumnos creyeran lo que no debían creer; para ponerlos a salvo del error, de la herejía, del relativismo moral.

Hay, desde luego, muchas cosas que nos resultan cuestionables en este modo de comprender y de enseñar filosofía. No por ello, sin embargo, deja de ser interesante la manera como se presentan las ideas con claridad y precisión, el orden en la exposición de los conceptos, cierto carácter sistemático y progresivo, e incluso un rigor lógico en la exposición del que tal vez hoy muchas veces carecemos. Ello no niega tampoco el hecho de que lo que se aprendía por medio del dictado calaba muchas veces en las mentes de los alumnos de forma bastante profunda. Releyendo el cuaderno de filosofía de mi padre he podido recordar muchas conversaciones que tuve con él, en las cuales me decía ciertas cosas que parecían sacadas de este cuaderno. ¿De dónde podrían provenir muchas de sus ideas en torno a la moral, la religión o incluso la metafísica que escuché de sus labios sino de este depósito de doctrina? ¿Por qué, entre los pocos papeles que dejó a la hora de su muerte, estaba precisamente este viejo cuaderno?

¿Qué puede uno ver a través de un viejo cuaderno de filosofía como este? ¿Qué nos muestra este viejo cuaderno? ¿Qué nos revelan unos textos como los que hemos leído y, en general, este cuaderno que es todo semejante a esos dos pasajes que he presentado? A través de él se nos revelan varias cosas. Quiero insistir en tres fundamentales.

En primer lugar, una práctica pedagógica en filosofía. Ya lo decía: la filosofía se enseñaba como una forma de transmitir y fijar una concepción del mundo preestablecida. Y eso implica, en primer término, que habría una "visión correcta del mundo" que todos deberíamos compartir; que, por tanto, todos deberíamos aprenderla y, con ello, saber qué es lo que se debe creer, lo que es correcto creer y cuáles son los errores en que no se debe incurrir; e implica, sobre todo, que se deberían identificar muy claramente los enemigos del entendimiento, que eran al mismo tiempo los enemigos del alma: el materialismo, el panteísmo, el ateísmo, el comunismo. Habría que ponerse en guardia contra todo ello. 
Puesto que se trataba de una visión del mundo que debía ser enseñada como un todo y aprendida como un todo, enseñar algo era trasmitir un conjunto de verdades establecidas. De esta manera - esto es lo segundo que quiero destacarenseñar filosofía era transmitir verdades que se suponian universales sobre los objetivos básicos de los que se debería ocupar la filosofía, entendida básicamente como metafísica: Dios, el alma y el mundo. La filosofía se convertía así en el saber supremo por los objetos de que se ocupaba. Es claro, desde luego, que no se enseña filosofía de una cierta manera sin que a través de ello se nos revele una concepción implícita de aquello que se cree que es la filosofía. ¿Qué era, entonces, la filosofía? Una ciencia sobre verdades últimas y por ello la ciencia que debía aprender todo aquel que quisiera ser una persona educada, juiciosa; una buena persona, un buen ciudadano, un buen cristiano.

Pero aquí se nos revela algo aún más fundamental que una concepción de la filosofía y un modo de enseñar filosofía - esta es mi tercera observación-: se nos revela un tipo de sociedad, una sociedad cerrada de carácter predemocrático. Se trata de una sociedad que se concibe a sí misma como algo que debe ser autorreproducido, como algo que existe para su propia perpetuación, como algo que debe ser conservado a toda costa. La sociedad existe no para avanzar, no para buscar nuevas perspectivas, no para que haya diversidad, sino para autopreservarse. De hecho, toda la educación estaba puesta al servicio de preservar y conservar la sociedad establecida; y, sobre todo, de preservar y conservar jerarquías y privilegios. La filosofía se convertía, en cuanto ciencia sobre verdades últimas, en aquello que daba la sanción final a las premisas sobre las que se constituía esa sociedad ordenada a su propia preservación.

Pero dejemos aquí, por ahora, este viejo cuaderno de filosofía, escrito hace ya casi un siglo, para volver de nuevo nuestra mirada hacia el presente. Sobre todo, salgamos del círculo cerrado de una sociedad hecha para su continua reproducción. Reconozcamos que, en el tiempo que nos separa de este objeto que hasta aquí hemos contemplado, han cambiado muchas cosas. No solo ha cambiado la filosofía y el modo de enseñarla, sino que ha cambiado algo más fundamental: ha cambiado la sociedad misma, para hacerse más democrática, más abierta y pluralista, con los pros y contras que ello pueda implicar. Situémonos, pues, en un nuevo marco para pensar la enseñanza filosófica. 


\section{La democracia como supuesto de la educación filosófica}

ES UNA AFIRMACIÓN FÁCIL decir que vivimos ahora en tiempos más propicios para la democracia. Varios acontecimientos del último año bien nos podrían hacer creer que vivimos una época de profundo "odio a la democracia”, para utilizar la sugerente expresión de Jacques Rancière (2007). Debo decir sin embargo que, cuando me refiero aquí a la democracia, no lo hago básicamente en el sentido de una forma de gobierno -es decir, no me refiero en sentido estricto a la democracia política-, sino a la democracia como modo de vida en el sentido en que lo ha desarrollado John Dewey ${ }^{1}$. Si bien aprecio muchas de las transformaciones sociales y políticas que hemos experimentado en nuestro país a raíz de la Constitución Política de 1991 y tengo sinceras esperanzas en que los recientes acuerdos de paz generen nuevas posibilidades de convivencia en medio del conflicto, lo que quiero destacar al hacer de la democracia el supuesto fundamental de una educación filosófica es el hecho de que la filosofía y su enseñanza deben ser repensadas en conjunto y dentro del marco de una sociedad mucho más móvil, abierta y pluralista que la que vivimos hasta hace unos años.

Vivimos en una sociedad donde - a diferencia de las sociedades tradicionales, ordenadas por la autopreservación- el cambio es lo único permanente. Una sociedad democrática es, en este sentido, aquel tipo de sociedad que, lejos de adquirir una forma única y definitiva, se constituye a partir de su posibilidad de introducir cambios permanentes y, sobre todo, de responder a las nuevas exigencias que plantean los múltiples movimientos que se dan en la economía, la política, la cultura, y del surgimiento de nuevas y muy plurales identidades. En una sociedad así es inevitable que la filosofía tenga que encontrar un nuevo lugar y es necesario que su enseñanza se transforme. Ya no podrá ser, desde luego, esa ciencia de verdades últimas que deba ser enseñada como forma de apuntalar una visión correcta del mundo, precisamente porque la idea de una visión correcta del mundo es incompatible con la idea de una sociedad democrática. Deberá ser ahora, más bien, una de las herramientas intelectuales por excelencia -junto a la ciencia, el arte, la política, la religión- por medio de las cuales una sociedad

1 Sobre la concepción de democracia de John Dewey, véase La democracia como forma de vida (Dewey, 2017). Se trata de una selección de quince textos escritos a lo largo de más de cincuenta años y en donde se conserva como noción clave esta idea de democracia como forma de vida. 
alcanza un grado mayor de autoconciencia y está en condición de enfrentar de modo más inteligente los diversos problemas humanos.

Desafortunadamente, como lo hemos visto hasta aquí en nuestro examen de un viejo cuaderno de filosofía y como a menudo se refleja en algunas de nuestras prácticas filosóficas habituales, de carácter apologético, racionalizador y autojustificatorio, la filosofía ha servido más a la preservación del statu quo que a un ejercicio crítico y proyectivo de nuestro conocimiento y nuestra acción. En un texto escrito hace exactamente un siglo, en 1917, el filósofo norteamericano John Dewey se quejaba de esta función conservadora de la filosofía y señalaba la necesidad de recuperar para ella su función crítica y proyectiva de la experiencia presente. Dice allí Dewey (1982 [1917]):

La filosofía [...] es inusualmente conservadora, no necesariamente en ofrecer soluciones, sino en aferrarse a problemas. Ha estado tan aliada con la teología y la moral teológica, como representativas de los principales intereses de los hombres, que la alteración radical le ha resultado chocante. Las actividades de los hombres tomaron decididamente un nuevo giro, por ejemplo, en siglo XVII, y parecía como si la filosofía, bajo la guía de pensadores como Bacon y Descartes, fuera a cambiar radicalmente de postura. Sin embargo, a pesar del fermento, lo que ocurrió fue que muchos de los viejos problemas solo fueron traducidos del latín a las lenguas vernáculas o a la nueva terminología suministrada por la ciencia.

La asociación de la filosofía con la enseñanza académica ha reforzado este conservatismo intrínseco. La filosofía escolástica persistió en las universidades después de que los pensamientos de los hombres por fuera de las paredes de los claustros se habían movido en otras direcciones. En los últimos cien años los avances intelectuales en cuestiones de ciencia y de política tomaron forma y se fueron cristalizando en un material de instrucción que ahora se resiste a un cambio posterior. Yo no diría que el espíritu de la enseñanza es hostil al de la investigación libre, pero una filosofía que existe sobre todo como una cosa que debe ser enteramente enseñada, más que como algo sobre lo que se debe reflexionar, conduce a la discusión de puntos de vista mantenidos por otros más que a una respuesta propia, no mediada. Cuando se enseña filosofía inevitablemente se magnifica la historia del pensamiento pasado, pues se conduce a los filósofos profesionales a aproximarse a su materia a través de su formulación en sistemas de pensamiento ya aceptados. Se 
tiende también a enfatizar los puntos sobre los cuales los hombres se han dividido en escuelas, para darle a esos puntos una definición y elaboración retrospectivas. En consecuencia, la discusión filosófica es como un muestrario de tradiciones antitéticas, donde se cree que la crítica de una opinión proporciona la prueba de la verdad de su opuesta (como si la formulación de un punto de vista garantizara exclusiones lógicas). La preocupación directa por las dificultades contemporáneas se deja a la literatura y la política (pp. 3-4; la traducción es mía).

Hay, pues, nos sugiere Dewey, un vínculo estrecho entre ese conservatismo que parece intrínseco a todas las escuelas filosóficas (incluso a aquellas que, aunque se piensan revolucionarias, comparten el mismo lenguaje y los mismos presupuestos y esquemas conceptuales de las tradiciones filosóficas consagradas) y el modo en que la filosofía suele ser enseñada. Una filosofía que existe como algo que debe ser enseñado como un todo es necesariamente una forma de reproducir un esquema de vida prefigurado. Lo que debería pedirse a la filosofía, pensaba Dewey, es algo bien distinto: un redireccionamiento de los pensamientos del hombre común, más que de los filósofos profesionales, en orden a comprender de una forma crítica y proyectiva lo que requieren las nuevas tendencias del conocimiento, las costumbres sociales, las prácticas políticas y estéticas y las nuevas configuraciones de la individualidad que se dan en el mundo contemporáneo. Dice Dewey (1982 [1917]):

Si alguna vez el cambio de conducta y la expansión del conocimiento han requerido una buena disposición para no rendirse, no solamente ante las viejas soluciones sino también ante los viejos problemas, es ahora. Con esto no quiero decir que podamos deshacernos abruptamente de todos los asuntos tradicionales. Esto es imposible; sería la ruina de quien lo intentara. Independientemente de la profesionalización de la filosofía, las ideas que los filósofos discuten son todavía aquellas en las cuales la civilización occidental ha sido formada. Son las ideas que están en las cabezas de las gentes educadas. Pero lo que los hombres de intención sincera no involucrados en el negocio profesional de la filosofía más desean saber es qué modificaciones y abandonos de herencia intelectual son los que requieren los nuevos movimientos industriales, políticos y científicos. Ellos desean saber qué es lo que esos nuevos movimientos significan cuando son traducidos a ideas generales. A menos que la filosofía profesional pueda movilizarse suficientemente para 
ayudar en esta clarificación y redirección de los pensamientos de los hombres, es probable que se desvíe cada vez más de las principales corrientes de la vida contemporánea (p. 4; la traducción es mía).

La necesidad de responder a los nuevos movimientos económicos, políticos y culturales a través de una comprensión de lo que ellos implican en términos de ideas más universales de que nos habla aquí Dewey implica que la filosofía misma se transforme en otra cosa que una ciencia de verdades últimas y, por tanto, que renuncie de forma definitiva a la pretensión de una filosofía perenne. De allí se sigue, además, que la filosofía, en una sociedad abierta al cambio y a la diferencia no puede ser enseñada como una visión correcta del mundo, sino como una herramienta de comprensión y cambio de perspectivas. Ello le implica, además, que debe descentrarse, salir de sí misma y convertirse en un modo de examinar los problemas humanos que dé cuenta de ellos desde una perspectiva que es a la vez crítica y reconstructiva. Dewey (1982 [1917]) es radical en este punto:

No es necesario -y ni siquiera es deseable-, que la filosofía se nos presente como un programa preestablecido. Hay dificultades humanas urgentes y profundamente arraigadas que pueden ser clarificadas por medio de la reflexión formada y cuya solución se puede obtener a través del cuidadoso desarrollo de hipótesis. Cuando esto se comprende, y cuando el pensamiento filosófico queda implicado en el curso efectivo de los eventos, en donde tiene el oficio de guiar dichos eventos hacia un desarrollo más próspero, los problemas se presentarán de forma abundante. La filosofía no resolverá dichos problemas, pues la filosofía es visión, imaginación, reflexión, y esas funciones, apartadas de la acción, no modifican nada; y, por tanto, tampoco resuelven nada. Sin embargo, en un mundo complicado y perverso, la acción que no está informada por la visión, la imaginación y la reflexión es más probable que incremente la confusión y el conflicto en vez de ayudar a aclarar las cosas. No es fácil para la reflexión generosa y constante llegar a convertirse en un método que guía e ilumina la acción. Hasta que la filosofía no logre liberarse de la identificación con problemas que, se supone, dependen de la Realidad como tal, o de su distinción entre la Realidad y un mundo de apariencias, o de su relación con un Conocedor como tal, tendrá sus manos atadas. En cuanto no tenga oportunidad de vincular sus propias peripecias con un desempeño responsable que sugiera el tipo de cosas que deben ser tratadas, no podrá la filosofía identificarse con aquellas cuestiones que 
efectivamente surgen en las vicisitudes de la vida. La filosofía solo se recuperará a sí misma cuando deje de ser un dispositivo para tratar los problemas de los filósofos y se convierta en un método, cultivado por los filósofos, para tratar con los problemas de los hombres (p. 46; la traducción es mía).

No es difícil percibir en un texto como este que el gran filósofo norteamericano pretendía encontrar un lugar más propicio para la filosofía en un mundo que se percibe a sí mismo como abierto y democrático. Ya la filosofía no tendría por qué responder a un programa preestablecido, sino acompañar las diversas indagaciones y descubrimientos humanos para descubrir problemas a los que podría aportar una comprensión más elevada -aunque no pudiera solucionarlos, pues su función sería siempre reflexiva e imaginativa-. Una filosofía permeada efectivamente de un espíritu democrático habría de ocuparse, más que de los problemas de los filósofos, de los problemas efectivos de los hombres con la ayuda de los métodos y herramientas que proporciona ese modo peculiar de explorar los problemas humanos que los antiguos griegos llamaron "amor por la sabiduría”.

El problema más específico de la relación entre filosofía y democracia fue abordado por Dewey poco tiempo después en una conferencia pronunciada ante la Philosophical Union de la Universidad de California el 29 de noviembre de 1918, que fue luego publicada como "Filosofía y democracia" en el tomo 11 de sus Middle Works (1977 [1918])MW 11:, p. 41-53). Allí, después de hacer una crítica demoledora de la pretensión tradicional de que la filosofía fuese en sentido estricto una ciencia, y menos aún una ciencia que conoce una realidad más fundamental que la de otras ciencias, propone una visión alternativa de la filosofía que recupere su sentido original y etimológico de "amor por la sabiduría" y que describe en estos términos:

[...] debemos retornar al sentido original y etimológico de la palabra y reconocer que la filosofía es una forma de deseo, de esfuerzo por actuar; que es una forma de amor, a saber, el amor por la sabiduría; con esta estipulación tan precisa no me acojo, sin embargo, al uso de esa palabra, sabiduría, que hace Platón; la sabiduría, cualquier cosa que ella sea, no es un modo de ciencia o conocimiento. Una filosofía que fuese consciente de su propio negocio y del terreno que le es propio percibiría que ella es un deseo intelectualizado, una aspiración por someterlo todo a la discriminación y el examen racional, una esperanza social por reducirlo todo a un programa de acción que 
funcione efectivamente, una profecía del futuro, pero todo esto disciplinado por un pensamiento y un conocimiento serios (Dewey, 1977 [1918], p. 43; la traducción es mía).

Este "amor por la sabiduría”, subrayará más adelante Dewey, es algo distinto al entusiasmo por el conocimiento científico, aunque no se pueda hacer un trabajo filosófico serio sin una familiaridad suficiente con los desarrollos de las diversas ciencias, pues ese "deseo intelectualizado" en que consiste el filosofar supone que ese esfuerzo apasionado por alcanzar la sabiduría se vea modulado por la disciplina de un conocimiento confiable y riguroso. Al hablar de la filosofía como sabiduría, más que como ciencia, lo que se quiere subrayar es el hecho de que estamos no ante un asunto de conocimiento, sino de actitudes y de acciones, ante un hecho moral:

[c] on el término sabiduría no nos referimos a un conocimiento de hechos y verdades sistemáticas y comprobadas, sino a una convicción acerca de los valores morales que tienen sentido para ese mejor tipo de vida que pretendemos llevar. Sabiduría es un término moral, y como todo término moral, no se refiere a la constitución de las cosas que ya existen, y ello ni siquiera en el caso de que dicha constitución se magnifique confiriéndole a esas cosas eternidad y carácter absoluto. En cuanto término moral, este se refiere a una elección acerca de lo que se debe hacer, una preferencia por vivir este tipo de vida más que aquel; su punto de referencia no es, entonces, una realidad ya terminada, sino ese futuro deseado al cual nuestros deseos, cuando se traducen en convicciones articuladas, pueden ayudar a llevar a la existencia (Dewey, 1977 [1918], p. 43; la traducción es mía).

En esta bellísima conferencia, Dewey dice algo que recordé una y otra vez leyendo el cuaderno de filosofía de mi padre. Según él, si nos ponemos a estudiar la filosofía que se nos ha transmitido por siglos - no sólo la antigua, sino incluso la moderna- encontraremos que hay allí una serie de nociones que son totalmente irrebatibles e indiscutibles, pues todos -los filósofos y los no filósofos- las aceptan y comparten. Un ejemplo muy claro y significativo de ello es la noción de que existe una distinción necesaria entre algo que, por naturaleza, es "superior" y algo que, también por naturaleza, es "inferior". Si recordamos ahora lo que leímos sobre la crítica al panteísmo en nuestro viejo cuaderno de filosofía, uno de los argumentos en que se apoyaban los maestros de entonces para criticar y refutar el panteísmo era 
que, además de conducir al ateísmo (e incluso ser peor que este), era que tenía terribles consecuencias morales, una de las cuales era precisamente que, puesto que igualaba todo, no reconocía diferencia entre "lo inferior" y "lo superior"; al afirmar una identidad entre "lo inferior" y "lo superior", resulta imposible justificar la existencia de la ley; y, si ello fuera así, tampoco habría moral posible. Dewey tiene una certera expresión para referirse a este asunto: dice que toda la filosofía que hemos enseñado hasta hoy está al servicio de una "metafísica del feudalismo"2. Quiero llamar la atención sobre el poder de esta expresión: metafisica del feudalismo. Lo que quiere decir el filósofo norteamericano es que la filosofía ha sido también un modo de preservar y de buscar justificación para el orden establecido, con todas sus diferencias, desigualdades, jerarquías, privilegios; ello implica que la filosofía misma, y con ello su enseñanza, deben ser pensadas desde supuestos distintos a los de la metafísica del feudalismo y que, por tanto, como lo subrayó en su momento Richard Rorty (1986), la democracia es condición y supuesto del propio filosofar.

He hecho la descripción de lo que era estudiar filosofía hace casi noventa años para mostrar cómo había una manera de entender la enseñanza de la filosofía y la filosofía misma, que además reflejaba un tipo de sociedad de carácter predemocrático. Evidentemente, en una sociedad democrática la cosa tiene que ser distinta; y

2 Dice Dewey (1977 [1918]): “[...] quizás no sea tan evidente que la desigualdad significa en términos prácticos inferioridad y superioridad, y que esta relación funciona prácticamente como soporte de un régimen de autoridad o de jerarquía feudal en el cual cada elemento más bajo o inferior depende, y se sostiene en, algo superior que le otorga dirección y del cual dicho superior se hace responsable. Permítase cada uno retener plenamente esta idea en su mente y verá cuán fuertemente la filosofía ha estado comprometida con una metafísica del feudalismo. Lo que quiero decir con esto es que existe la idea de que las cosas en el mundo están ocupando ciertos grados de valor, o que existen grados fijados de verdad y rangos de realidad. La concepción tradicional de la filosofía a la cual me referí al comienzo, que se identifica con la intuición de una realidad suprema o última y con la idea de una verdad comprehensiva, es una muestra de cuán fuertemente la filosofía ha estado asociada a la noción de que algunas realidades son inherentemente superiores, o inherente mejores, que otras. Ahora bien, cualquier filosofía de este tipo opera de forma inevitable en medio de un régimen de autoridad para el cual lo único correcto es que lo superior gobierne sobre lo inferior. El resultado de ello es que gran parte de la filosofía ha servido para justificar este particular esquema de autoridad que ha existido en un determinado tiempo en la religión o en el orden social. La filosofía ha llegado a convertirse entonces, inconscientemente, en una apologética del orden establecido, puesto que ha tratado de mostrar la racionalidad de este o aquel grado jerárquico de valores y de esquemas de vida; o, cuando ha cuestionado el orden establecido, esto se ha hecho por medio de una búsqueda revolucionaria de algún principio de autoridad que se le presente como rival. Hay que ver cuán fuertemente la filosofía histórica ha estado en la búsqueda de un sitial de autoridad que resulte inamovible" (p. 51; la traducción es mía). 
tiene que ser distinta porque en una sociedad democrática tenemos que empezar a cuestionar muy seriamente la metafísica del feudalismo. En una sociedad democrática tenemos que empezar por reconocer que puede y debe haber concepciones de mundo alternativas, esto es, que es legítimo y deseable que haya creencias diversas: políticas, religiosas y de todo tipo; y que haya diversidad sexual, social, cultural, étnica. Por esta razón, en una sociedad democrática - diversa, abierta, multicultural, pluriétnica - la filosofía no puede estar al servicio de una única visión del mundo. Una filosofía realmente democrática parte del reconocimiento de que hay perspectivas distintas y, por tanto, de que si la filosofía se enseña, no se enseña para fijar una visión única del mundo, sino para ofrecer herramientas orientadas a la crítica de las prácticas y los saberes establecidos.

Hoy concebimos la filosofía como crítica de las prácticas culturales, como crítica de los saberes; y por eso la filosofía mantiene, y debe mantener, un diálogo abierto con los distintos saberes y culturas; por eso también la filosofía tiene que salir cada vez más a la calle y conversar con todos. Nos resulta inaceptable, entonces, una concepción de la filosofía como doctrina o como visión correcta del mundo. Decía Marx (1938) en su famosa tesis XI sobre Feuerbach, que la filosofía debía transformar el mundo, pues no bastaba con interpretarlo. Esto, desde luego, es bastante deseable; y yo creo que, de algún modo, la filosofía transforma el mundo en cuanto transforma nuestras formas de percibirlo, de concebirlo, de actuar sobre él. Sin embargo, creo también que la filosofía no necesita transformar el mundo, pues el mundo se está transformando permanentemente. El mundo se transforma sobre todo cuando los que vivimos en una determinada comunidad, nosotros, los ciudadanos, pretendemos que es posible transformar de forma reflexiva nuestras prácticas y cuando somos capaces de acercarnos a otras culturas, a otras concepciones de mundo, y nos dejamos enriquecer por ellas. La conformación de un modo de vida democrático es algo que, por el concepto mismo que nos hacemos de ella, está en permanente creación y en permanente reconstrucción, como modo de gobierno y como cultura, es decir, como modo de organización de las distintas dimensiones de la vida ciudadana.

¿Qué implicaciones tiene lo anterior para la enseñanza de la filosofía? La primera y más evidente es, desde luego, que la filosofía no puede ya ser enseñada como una visión correcta del mundo que debe ser enseñada y aprendida como una totalidad, pues ello se contrapone abiertamente al espíritu democrático. La 
filosofía y su enseñanza deben ser pensadas ahora desde la perspectiva del papel que juegan en la formación del ciudadano de una sociedad más abierta, pluralista y democrática. No se trata ya simplemente de enseñar un cuerpo de conocimientos, pues la filosofía es mucho más que eso. La filosofía es una actitud, un modo de vida, eso que los antiguos griegos, que fueron los reales inventores de la filosofía, llamaron "sabiduría". Ese tipo de sabiduría que es la filosofía es profundamente esencial para una sociedad democrática, pues una sociedad democrática es impensable sin el concurso crítico de la filosofía.

Pero, por otra parte, y esta es la consecuencia que considero más fundamental, el propio desarrollo de la disciplina filosófica y las necesidades inherentes a un modo de vida democrático suponen encontrar un nuevo lugar para la filosofía en la educación. Ya no se trata solo de intentar comprender en qué pueda consistir aprender y enseñar filosofía como una disciplina más que ha de estar presente en los currículos, sino que es preciso pensar en ella como algo que está a la base de toda educación. Más que enseñar filosofía, hoy se trata de promover una educación filosófica. La noción de educación filosófica es mucho más amplia que la de la enseñanza de la filosofía como disciplina, aunque, por supuesto, dentro de un proyecto más amplio de educación filosófica, la enseñanza de la filosofía como disciplina -y, dentro de ella, el conocimiento de la tradición filosófica- es un elemento central y definitivo, pero no único.

La idea de educación filosófica se apoya en por lo menos dos presupuestos básicos. El primero es que la filosofía es un bien público abierto a todos. Durante muchos siglos no fue así. La filosofía era algo de unas pocas élites, un saber cerrado que solo podían cultivar ciertas personas o de cierta edad o de cierta condición social. Hoy la filosofía tiende a ser cada vez más un bien público sin limitaciones de edad. Ya no es solo para los adultos; es también para los niños, para los jóvenes y, por supuesto, para las mujeres. Ya no importa tanto si se tiene tal creencia política o religiosa o tal condición social o económica. La filosofía empieza a ser, y tiende a ser cada vez más, un bien público abierto a todos. El segundo presupuesto de la idea de educación filosófica es que el aprendizaje filosófico no se limita a una disciplina, sino que se lo considera posible en otros campos del saber; es decir, que no solo hay, o puede haber, aprendizaje filosófico cuando se enseña filosofía, pues la filosofía no es solo una disciplina: es un modo posible de aprender cualquier disciplina. Se puede pensar, entonces, en un proyecto de 
educación filosófica en el campo de las matemáticas, de las ciencias naturales, de las artes, e incluso de la educación corporal.

Una consecuencia necesaria de este segundo presupuesto es que la filosofía no queda encerrada -como tampoco, desde luego, la educación filosófica- en los espacios académicos. La filosofía no es algo que pertenece, por ejemplo, exclusivamente a la universidad, sino que, cada vez más, la filosofía, como bien público, se extiende a las calles, a los cafés, a las instituciones culturales (como los museos, los centros culturales y otros), y puede hasta practicarse en las cárceles. Hoy hay experiencias muy interesantes de trabajo filosófico por fuera de las aulas escolares y universitarias y se abren espacios nuevos para ella en ambientes virtuales. Para comprender mejor esto último será necesario, sin embargo, que hagamos un pequeño excurso en nuestra reflexión para hacer una descripción un poco más detallada de cómo la propia enseñanza de la filosofía como disciplina ha venido sufriendo en los últimos años una serie de desplazamientos y transformaciones.

\section{Desplazamientos y transformaciones en la enseñanza y el aprendizaje de la filosofía}

EN UNA SOCIEDAD QUE PRETENDE ser democrática, la filosofía y su enseñanza han venido cambiando para responder a nuevas exigencias. Se trata de desplazamientos y transformaciones que obedecen a la necesidad de adaptación del saber y las prácticas filosóficas a una sociedad que, como la sociedad democrática, debe estar en perpetuo movimiento y transformación. Aunque la descripción que haré a continuación está lejos de ser exhaustiva, servirá al menos para mostrarnos, como en un collage, todas las cosas que han cambiado en el modo de hacer filosofía, y de enseñarla, así como la necesidad de acometer una profunda y comprehensiva reestructuración de la filosofía y su enseñanza que resulte acorde con los tiempos que vivimos.

La aparición de nuevos campos de trabajo filosófico. Se creía que había una única filosofía o una filosofía perenne. Hoy se reconoce que hay muchas filosofías, que hay muchos modos distintos de trabajo en filosofía y que la filosofía es algo que, como toda disciplina, se encuentra en permanente transformación. Más que de una filosofía, sería preciso hablar de múltiples filosofías, e incluso de filosofías alternativas. De otra parte, a medida que las distintas ciencias se fueron desarrollando 
(primero las ciencias naturales, luego las ciencias sociales), fueron apareciendo muchas "filosofías de...." Hoy hablamos, por ejemplo, de filosofía del lenguaje o de filosofía de la física o de filosofía de la economía, o de la psicología, en la medida en que las ciencias se van zafando de la tutela de la filosofía, también, y al mismo tiempo, la filosofía empieza a dialogar con ellas y empiezan a generarse diversas "filosofías de..." También, y a medida que se desarrollan ciertas disciplinas, aparecen campos filosóficos específicos; por ejemplo, el desarrollo de la inteligencia artificial tuvo un gran impacto posteriormente sobre el surgimiento de lo que se llamaría después la filosofía de la mente. Así mismo, la aparición de diversos tipos de problemas -por ejemplo, en el campo de la salud, o en el campo ambiental o en el campo de los negocios- ha dado lugar a muchas éticas aplicadas. También la búsqueda de identidad por parte de múltiples culturas ha dado lugar a filosofías muy ligadas a ese proceso de búsqueda de identidad cultural, lo que se traduce en la creación de una filosofía latinoamericana, o de una filosofía africana, o de una filosofía oriental (china, japonesa, entre otras) en diálogo directo con la filosofía de Occidente. Pero, además, la filosofía discute con otras perspectivas y trabaja con profesionales de otras disciplinas y empieza a generarse, y la filosofía empieza a participar en él, un novedoso trabajo interdisciplinario.

Lo que es claro es que la filosofía no es ya, como se decía antes, "la reina (o la madre) de todas las ciencias". No, ahora la filosofía, y los filósofos, tienen que sentarse a la mesa en igualdad de condiciones con todas las otras disciplinas, para tener con ellas un diálogo abierto y libre de prejuicios. Como le pasa a una madre cuando sus hijos crecen, la filosofía no puede invocar una autoridad que, aunque aún tiene, debe deponer para dialogar cara a cara con los demás saberes, para ampliar su propia perspectiva y para encontrar campos de trabajo en común. De esta manera, al aparecer nuevos campos de trabajo filosófico, la filosofía como disciplina se amplía, adquiere nuevas perspectivas y emprende nuevas búsquedas. Estamos lejos de aquellos tiempos en que había una única filosofía, una filosofía perenne, que todos debían aprender.

El segundo acontecimiento clave que se debe poner de presente es el surgimiento de nuevos interlocutores filosóficos. Hasta hace unos años la filosofía tenía el rótulo de ser "solo para adultos", además adultos varones e ilustrados. Hoy en día la situación ha cambiado radicalmente: han aparecido nuevos interlocutores filosóficos. Ya no es solamente el adulto varón e ilustrado el que debe y puede tener acceso 
a la filosofía. Tampoco la filosofía es ahora algo que está encerrado en las aulas universitarias, y por casualidad en algunas aulas de bachillerato. Ya nadie puede decir que tiene el monopolio del estudio o la práctica de la filosofía. Si la filosofía realmente participa del espíritu de una sociedad democrática, debe ser algo abierto a todos, sin distinción de edad, de condición social, sexual, económica.

Veamos algunos de esos nuevos interlocutores filosóficos a los que me acabo de referir. Las mujeres, por ejemplo, han ido ganando en los últimos años una presencia en la discusión filosófica que no tenían hasta hace un tiempo, no solo porque participan en el aprendizaje filosófico con cada vez mayor rigor y originalidad, sino porque, además, hay quienes se han empezado a interesar cada vez más por la perspectiva de género en la filosofía. En la filosofía, la mujer no simplemente participa como un interlocutor más, sino que tiene una perspectiva distinta. Hasta hoy la filosofía ha sido tremendamente varonil y eso le plantea limitaciones en su perspectiva y en el modo como se abordan los problemas que se someten a su reflexión. La perspectiva femenina en filosofía obliga al replanteamiento de muchas perspectivas en el tratamiento de temas tan fundamentales como la ética o el estudio de las emociones, entre otros.

También los niños y los jóvenes han ido adquiriendo un lugar propio y relevante en el panorama filosófico mundial. El impacto que ha tenido en los últimos cuarenta años el desarrollo de la filosofía con niños y jóvenes en todo el mundo (impacto que se ha debido, entre muchas otras cosas, a la difusión del trabajo pionero de Matthew Lipman y Ann Margaret Sharp) no solo ha llevado a que en muchas partes la filosofía ocupe un lugar propio en la enseñanza básica primaria y secundaria, sino a que los niños y jóvenes desarrollen un interés por la filosofía que hasta entonces no existía y que se manifiesta de muchas maneras distintas: la discusión filosófica entre niños y jóvenes a través de Internet, el surgimiento de una literatura filosófica para niños y jóvenes, los congresos escolares de filosofía, las Olimpiadas de Filosofía. La sola idea de hacer filosofía con niños nos obliga a los filósofos a un cambio de perspectiva en nuestro propio trabajo como filósofos, pues nos implica estar más atentos a lo que sucede en su mente y en su contexto, al modo como razonan y como construyen significados para un mundo que empiezan apenas a construir.

$\mathrm{Al}$ interés cada vez mayor de profesionales de otras disciplinas por los estudios filosóficos (médicos, abogados, ingenieros, economistas) viene a sumarse el 
hecho de que muchas personas sin un interés teórico muy explícito, es decir hombres del común (por ejemplo, amas de casa o empleados de empresas estatales y privadas), se interesan cada vez más en participar en actividades filosóficas de carácter abierto, como los cafés filosóficos, las terapias filosóficas, los cursos filosóficos abiertos al gran público, grupos informales de estudio filosófico. Se trata, en general, de personas a las que les atrae tratar ciertos temas que tienen que ver con sus relaciones personales, con las preguntas existenciales que se plantean, con el simple placer de discutir temas que les inquietan sin ninguna pretensión sistemática, no porque quieran graduarse de filósofos, sino por el simple gusto y fascinación de discutir acerca de asuntos que les inquietan. Si consideramos legítimo este interés, nuestra responsabilidad como filósofos está en pensar nuevos formatos en los cuales sea posible desarrollar el ejercicio filosófico entre públicos tan diversos.

Quisiera insistir aquí en el sentido del término que he elegido para referirme a este fenómeno: interlocutores. No se trata de clientes, ni de simples escuchas; tampoco son alumnos. Reconocer a otros como interlocutores es reconocer no solo que su perspectiva es válida, sino que resulta enriquecedora para todos. La filosofía antes tenía alumnos, hoy tiene cada vez más nuevos interlocutores; y la aparición de nuevos interlocutores filosóficos hace que la filosofía tenga que pensarse a sí misma y tenga que pensar que se puede hacer de otra manera. Nuevos interlocutores filosóficos implican nuevas formas de hacer filosofía; e implican, por supuesto, nuevas formas de aprender y enseñar filosofía.

Una tercera transformación esencial en las prácticas filosóficas es la de la aparición y desarrollo de las prácticas filosóficas extraacadémicas. Con el término "prácticas filosóficas extraacadémicas" me refiero a todas esas nuevas maneras de hacer filosofía que tienen lugar por fuera de las academias universitarias, aunque algunas de ellas tengan un vínculo directo con ellas, bien porque están preparadas desde la academia o porque son impulsadas y dirigidas muchas veces por profesores universitarios. Empecemos por hacer una lista muy rápida de algunas de estas prácticas, que seguramente ya muchos conocemos: los cafés filosóficos; las distintas formas de consultoría filosófica hoy existentes, que van desde la terapia individual hasta las asesorías filosóficas a grupos y empresas; los cursos filosóficos abiertos a un gran público (por ejemplo, cursos de extensión bajo la modalidad de la educación continua); los grupos informales de estudio filosófico, consistentes en personas que se reúnen regularmente a estudiar o discutir sobre un determinado tema 
con el apoyo de un filósofo; los libros de divulgación filosófica, que se han incrementado muchísimo en el último tiempo; los grupos de discusión filosófica a través de Internet, que pueden ser tan variados como grupos de filósofos profesionales interesados en un determinado tema filosófico o grupos de discusión filosófica de niños o jóvenes; las Olimpiadas de Filosofía, que se realizan en muchísimos países, entre ellos varios latinoamericanos.

La filosofía rompió hace ya mucho tiempo las barreras de las aulas universitarias, de la academia universitaria; y esto da qué pensar a quienes nos ocupamos profesionalmente de la enseñanza de la filosofía. No pretendo idealizar este tipo de iniciativas. En todas estas nuevas prácticas filosóficas hay esfuerzos magníficos e interesantes; pero, por supuesto, hay también a veces improvisación, y en algunos casos esnobismo y charlatanería. Abrir el ejercicio filosófico hacia nuevos escenarios no tiene por qué implicar la pérdida del rigor que dicho ejercicio requiere; y no hay por qué aceptar que hacer filosofía es decir cualquier cosa y de cualquier manera; ni mucho menos confundir la discusión filosófica seria con cualquier intercambio fácil de opiniones. Hay allí, sin embargo, algo interesante y los que nos dedicamos a la filosofía no debemos descalificar esas prácticas por simple desconocimiento, porque nos son ajenas o porque simplemente no nos gustan (Ceppas, 2004).

Una cuarta transformación que creo interesante, aunque hoy en día haya perdido parte de su impulso inicial, es el intento por construir una pedagogía filosófica. Se trata de una reflexión interdisciplinaria -en la que deberían participar a la vez filósofos, pedagogos, psicólogos, planificadores de la educación, entre otros- sobre el sentido, los objetivos, los contenidos, los métodos, las estrategias de evaluación del aprendizaje y la enseñanza de la filosofía como disciplina. Se trata de algo mucho más amplio y complejo que lo que ordinariamente se conoce como didáctica de la filosofía, que consiste en lo esencial en una reflexión sobre los métodos de enseñanza de la filosofía. Una pedagogía de la filosofía incluiría una didáctica, pero no se reduciría a ella, puesto que se trata de una reflexión filosófica sobre la enseñanza de la filosofía, y no solo sobre sus métodos de enseñanza. Implicaría, por ejemplo, una investigación de fondo sobre las prácticas de aprendizaje y enseñanza de la filosofía en los diversos momentos de la historia filosófica, así como en 
diversos países y culturas y, sobre todo, una reflexión interdisciplinaria en torno al sentido de la enseñanza de la filosofía en una sociedad democrática ${ }^{3}$.

Hay, sin duda, investigaciones valiosas sobre el tema; sin embargo, aparte de que en muchos casos sigue primando el interés didáctico, se trata de esfuerzos que aún siguen dispersos. Creo que, para empezar, hay que hacer un inmenso esfuerzo de recopilación y síntesis en orden a elaborar una visión de conjunto del problema. Pensar en la posibilidad de una pedagogía de la filosofía implica al mismo tiempo una reflexión teórica muy profunda sobre el sentido de enseñar y aprender filosofía en el mundo de hoy, un trabajo interdisciplinario, para ver cómo esto se inserta en un proyecto más amplio de educación democrática e incluso un cierto grado de trabajo experimental que permita contrastar diversos modelos y propuestas en relación con prácticas concretas de enseñanza y aprendizaje filosóficos.

El quinto punto que quiero señalar es la aparición de una (nueva) literatura filosófica adaptada al gran público y la posibilidad de incorporar las nuevas (y viejas) narrativas en el aprendizaje de la filosofía. Pongo los términos "nueva" y "viejas" entre paréntesis, pues esta "nueva literatura filosófica" es algo que existe ya desde hace varios siglos; y las narrativas que pueden incorporarse en el aprendizaje filosófico son tanto las más clásicas (el cuento, la novela, el teatro, etc.) como las narrativas digitales contemporáneas (el cine, la fotografía, el videojuego). La idea de que se puede escribir una literatura filosófica adaptada al gran público tomó fuerza con un texto que tuvo mucho impacto, El mundo de Sofía, de Jostein Gaarder $(1995)^{4}$. Por otra parte, se ha venido constituyendo en los últimos

3 Un punto de partida valioso para ello lo encuentro en un libro que, aunque está ya un poco viejo y desactualizado, sigue siendo una herramienta útil para los maestros que se inician en la práctica de la enseñanza filosófica en la educación media: la Didáctica de la filosofía, del peruano Augusto Salazar Bondy (1967). Este filósofo muestra de una forma seria, y muy didáctica, cómo se puede enseñar bien enseñada la filosofía y cómo los métodos que la tradición filosófica ha consagrado como válidos pueden ser implementados en un aula de clase con alumnos de bachillerato. Otro trabajo interesante en esta línea fue el del profesor argentino Guillermo Obiols (2002). Desafortunadamente estos dos maestros de la pedagogía de la filosofía murieron muy jóvenes y no alcanzaron a desarrollar suficientemente sus investigaciones. Hay también una interesante reflexión sobre la pedagogía filosófica en algunas revistas especializadas: la famosa Revista sobre la Enseñanza de la Filosofía, de la cual se publicaron varios números en Francia hacia los años setenta. En los últimos años han surgido revistas especializadas en el tema en países como Australia, Estados Unidos, España y Francia.

4 Fue sorprendente que un texto cuya temática era la historia de la filosofía se convirtiera en un gran bestseller. Yo personalmente creo que hay ejercicios de la literatura filosófica muchísimo mejores (sin duda, las novelas filosóficas escritas por Matthew Lipman son de una calidad filosófica y li- 
años un nuevo género: el de los cuentos filosóficos. Hoy en día se están publicando cada vez más cuentos filosóficos, o se están adaptando cuentos tradicionales para el trabajo filosófico. De todos modos, hacer filosofía a través del cuento, la novela y el teatro no es algo tan novedoso. Eso ya lo hicieron, por ejemplo, los enciclopedistas franceses, como Voltaire ${ }^{5}$ Diderot: muchas de sus obras filosóficas más importantes fueron cuentos y novelas; también los existencialistas franceses (por ejemplo, Gabriel Marcel, Jean Paul Sartre y Albert Camus) utilizaron el teatro como un vehículo filosófico.

Lo que hay detrás de todo esto es un intento por "dramatizar la filosofía", según la muy bella expresión de Matthew Lipman (2001). ¿Cómo es posible -se pregunta Lipman- presentar el pensar filosófico en moldes dramáticos? Y responde:

Cuando hablo de 'dramatizar la filosofia', tomo en consideración un amplio espectro de actividades diseñadas con el fin de suscitar el interés de diversos tipos de individuos hacia los problemas filosóficos: estudiantes universitarios, de educación media y básica, e incluso todos aquellos que desarrollan algún programa de formación, como los adultos que asisten a escuelas nocturnas, los jubilados y muchos otros. Dichas actividades pueden tomar la forma de biografías de los filósofos, autobiografías escritas por los propios filósofos, textos filosóficos escritos en forma literaria más que argumentativa, como alegorías, parábolas, dramas, películas, poesía, cuento; o novelas populares sobre historia de la filosofía, representaciones teatrales de obras filosóficas; o incluso ciertas combinaciones de la filosofía con otras formas de expresión como la música, la danza o la ópera (Lipman, 2001, p. 95) ${ }^{6}$

teraria infinitamente superior a El Mundo de Sofia); sin embargo, es innegable el impacto que ha tenido esta novela, traducida a muchos idiomas y leída por muchísimos jóvenes de todo el mundo, pues para muchos de ellos ha sido el primer acceso a la filosofía.

5 Una interesante muestra de cómo un filósofo moderno que tuvo una profunda influencia en su tiempo y en los siglos venideros, vertió muchas de sus reflexiones filosóficas en la forma de cuentos y novelas es el de Voltaire. Una versión de todos sus cuentos en prosa y verso fue publicada por el Fondo de Cultura Económica y Editorial Siruela en el año 2006 (Voltaire, 2006).

6 Se pueden hacer muchas cosas distintas. Se puede, por ejemplo, aprovechar los textos clásicos como el punto de partida para una reflexión filosófica, como lo ha hecho la filósofa norteamericana Martha Nussbaum. Yo mismo he hecho ese trabajo de plantear algunos problemas filosóficos leyendo El Quijote, las Aventuras de Sherlock Holmes o El Tünel de Ernesto Sábato. Es un ejercicio filosófico muy interesante, y también una forma novedosa de acercar a los jóvenes a la reflexión filosófica. 
La aparición de nuevas narrativas (como el cine, la fotografía o incluso los videojuegos) pueden suscitar nuevas reflexiones de los filósofos y habría que pensar cómo se podrían incorporar en el aprendizaje filosófico. Son muy conocidas las relaciones que establecen entre el cine y la filosofía autores como Gilles Deleuze; o ciertos textos de Walter Benjamin sobre las relaciones entre fotografía y filosofía. El cine y la filosofía, la fotografía y la filosofía: son temas sugerentes para la investigación y reflexión filosóficas; y deberían serlo también para una pedagogía filosófica. Incluso los videojuegos, que nos parecen una cosa tan mecánica, podrían tener un lugar en una nueva pedagogía filosófica. ¿Cómo es posible incorporar el videojuego en un ejercicio de educación filosófica? Habría que pensarlo más despacio, desde luego; pero podría ser un ejercicio muy interesante. Cuando se estudian los desarrollos recientes de los videojuegos se pueden ver su inmenso potencial educativo, pues no solo desarrollan coordinaciones visomanuales, sino que implican juegos de estrategia, de toma de decisiones, etc. ¿No podría haber también allí un interesante campo para el desarrollo de una pedagogía filosófica? El filósofo también tendría que poder hablar estos nuevos lenguajes, tan propios de los niños y jóvenes de hoy.

La sexta transformación a la que quiero referirme es la enseñanza de la filosofia integrada con otros saberes y la posibilidad de un aprendizaje filosófico de las disciplinas. Si bien la filosofía es no solo una disciplina, sino un modo de aprender, ello no quiere decir que la enseñanza filosófica deba ser algo carente de contenido. Dicho contenido, por otra parte, no tiene que ser necesariamente la tradición filosófica, sino el de otras disciplinas. ¿Por qué no se puede aprender filosóficamente al tiempo que se estudian, por ejemplo, los problemas de la física moderna o acontecimientos históricos tan fundamentales como la Segunda Guerra Mundial o nociones tan esenciales para la ciencia contemporánea como las de átomo o célula? En todas estas cosas están en juego problemas conceptuales que atañen de un modo directo a la filosofía 7 .

7 Conozco alguna experiencia de enseñanza integrada de la filosofía con la física en un colegio de la ciudad de Bogotá hace unos años. El profesor de Física y el de Filosofía hacían la clase juntos y era muy interesante ver, por ejemplo, cómo las primeras tesis de los presocráticos eran leídas a la vez por el profesor de Filosofía y el de Física, o cómo los descubrimientos de Galileo o las leyes de la gravitación de Newton se aprendían al tiempo que se discutían los problemas claves de la filosofía natural que dieron lugar a dichos descubrimientos científicos. Sé también de intentos por enseñar integradamente la Filosofía con las Artes en España, particularmente la pintura, la música y el cine. 
Creo, además, que se puede ir más allá de la enseñanza integrada de ciertos saberes y la filosofía hacia un aprendizaje filosófico de las disciplinas. Hay, por ejemplo, experiencias de aprendizaje filosófico de las matemáticas en Canadá (Daniel, 1997). Aunque se trata de algo que requiere un mayor desarrollo, ello no niega la posibilidad de pensar en este proyecto de un aprendizaje filosófico de las disciplinas (o a través de las disciplinas), pues lo que allí está supuesto es la idea muy sugerente de que cualquier aprendizaje puede llegar a ser un aprendizaje filosófico si se hace de una forma reflexiva, es decir, si al aprender nos hacemos las preguntas y hacemos el mismo proceso de elaboración conceptual que hicieron quienes fueron los pioneros en un determinado campo del conocimiento ${ }^{8}$.

He presentado los seis puntos anteriores porque ellos constituyen el presupuesto esencial de la parte propositiva de este escrito. Aunque esta tiene diez puntos básicos, bien podría decirse que en realidad la propuesta es una sola: la de desarrollar un amplio proyecto de educación filosófica para el cual en los puntos anteriormente tratados están algunos elementos básicos. Dicho proyecto, sin renunciar a la tradición de investigación y enseñanza rigurosas de la filosofía como disciplina, debería responder a las exigencias de una sociedad democrática y a los retos planteados por las nuevas prácticas filosóficas a las que acabo de referirme.

8 Recuerdo que hace unos años me invitaron a un congreso sobre la enseñanza de las ciencias naturales. Al principio estuve tentado a rechazar la invitación, pues nunca he sido profesor de ciencias naturales. Sí fui, sin embargo, por muchos años un alumno de ciencias naturales. Pensé, entonces, que podría decir algo desde mi perspectiva de ser a la vez un filósofo interesado en la educación y haber sido alguna vez un alumno de un curso de ciencias naturales. Empecé a recordar entonces, e hice toda una reconstrucción mental de ello, lo que significó para mí -por esa época un niño de diez años- intentar entender un concepto tan complejo como el de densidad. Se trata de un proceso muy complejo, pues implica confrontar reflexivamente las nociones intuitivas que en esa época manejaba (nociones, por ejemplo, como las de peso y volumen), hasta elevarme a un concepto científico tan complejo como el de densidad. ¿Cómo pasa uno de la noción intuitiva de peso al concepto científico de densidad? No puedo ahora entrar en todos los detalles de ese proceso, que he relatado con más detalle en otro texto (Pineda, 2008a), en donde busco poner de presente los múltiples conflictos que uno tiene de niño para hacer todas esas transiciones conceptuales. En la enseñanza de las ciencias naturales, allí donde nos vemos obligados a hacer un riguroso ejercicio de construcción y reconstrucción de conceptos, la filosofía podría ayudar muchísimo, pues su campo es precisamente este: el de la formación de conceptos. Aprender reflexivamente, ciencias naturales o cualquier otra disciplina, es aprender a manejar los conceptos claves de ese campo del saber; aprender a transitar reflexivamente de unos conceptos a otros; y, con ello, romper con las representaciones inmediatas que tenemos de las cosas. ¿No podría ser esto un caso auténtico de aprendizaje filosófico? 
Ese proyecto de educación filosófica tendría varias características. En primer lugar, tendría que ser un proyecto de carácter democrático, pues debería estar abierto a todas las edades (a los niños, a los jóvenes, a los adultos), a las personas con limitaciones (por ejemplo, con limitaciones físicas, e incluso a los enfermos); debería estar abierto a las distintas condiciones sociales, económicas; y, por supuesto, debería ser un proyecto abierto al diálogo con otros saberes y sensible a las particularidades culturales.

La segunda característica de este proyecto sería su carácter transdisciplinario pues, sin desconocer el valor de la tradición filosófica, debe ser algo que se haga en contacto con las demás disciplinas y en diálogo directo con las demás áreas del currículo. Pensando, por ejemplo, en la filosofía en el bachillerato, habría que pensar en cómo el aprendizaje de la filosofía puede estar ligado también al aprendizaje de las matemáticas, las ciencias sociales, etc.

Aquí insisto -este es el tercer componente esencial del proyecto- en la noción de aprendizaje filosófico. Es la idea de que se puede aprender filosóficamente en cualquier disciplina, porque aprender filosóficamente es, en lo esencial, aprender las cosas -voy a decirlo un poco aristotélicamente- "por sus primeros principios y por sus primeras causas". Uno puede conocer una ciencia en sus aspectos más generales y exteriores -eso, por cierto, es lo que ocurre con mayor frecuencia- cuando simplemente sabe el ABC de la ciencia, o sabe hacer ciertas operaciones y definir algunos conceptos, pero no es capaz de pensar un problema científicamente. Para pensar científicamente, para pensar matemáticamente, se necesita el recurso al aprendizaje filosófico.

En cuarto término, una educación filosófica debe incorporar las nacientes prácticas extraacadémicas en filosofía a las que ya hice referencia. Estas pueden incorporarse bajo la modalidad de lo que solemos llamar "actividades extracurriculares”, pero también como formas de llevar la educación filosófica más allá de las aulas y de abrir la reflexión filosófica a los espacios públicos. Un proyecto de educación filosófica, además, debe estar abierto a los nuevos desarrollos tecnológicos como un espacio para la interlocución filosófica. ¿Por qué no se pueden explorar Facebook, Twitter y otras redes sociales para buscar nuevas formas de interacción filosófica con los jóvenes? Si lo que queremos es llegar a ellos, tenemos que llegar en los lenguajes que ellos manejan. La tecnología hoy nos da acceso a los jóvenes y no hay que despreciar las nuevas formas de interacción que a través de 
ella son posibles; antes bien, es preciso buscar también un lugar para la filosofía en el ciberespacio. Finalmente, una educación filosófica debe tener un carácter internacional e intercultural. En los últimos años la UNESCO ha hecho un esfuerzo interesante por recuperar el papel de la filosofía en la educación; y hay proyectos interesantes de intercambios filosóficos interculturales?.

\section{Diez retos para la educación filosófica del futuro}

TERMINO, POR FIN, esta ya larga exposición con diez sugerencias o retos que considero esenciales para todos los que nos dedicamos a la enseñanza de la filosofía como disciplina y a la educación filosófica como proyecto vital.

Si uno quiere consolidar un proyecto de educación filosófica, ¿en qué debe trabajar?

1. Habría que empezar por el fortalecimiento de los estudios filosóficos de pregrado y posgrado. Considero esta la condición esencial para todo lo demás. Mientras la filosofía no forme parte de nuestra cultura, mientras no intentemos luchar por hacer del nuestro un pueblo culto, todos los demás esfuerzos se verán incompletos. Si queremos formar un pueblo culto, tendremos que dar un amplio espacio a la filosofía en nuestros currículos escolares y universitarios; y tenemos que fortalecer la investigación y la enseñanza filosófica en nuestro medio, pues la filosofía es una forma de autoconciencia que es esencial en la construcción de una cultura ${ }^{10}$.

2. Hay que esforzarse muy a fondo en la incorporación de metodologías de aprendizaje filosófico en las disciplinas y el cultivo de nuevas prácticas

9 En el año 2005 tuve la posibilidad de participar del Día Mundial de la Filosofía, en Chile, invitado por la UNESCO, y había allí un diálogo intercultural interesante, por ejemplo, de los filósofos de Latinoamérica con los filósofos de África. Poco tiempo después hubo también un encuentro de filósofos árabes y orientales. Todo lo que ayude a promover el intercambio cultural en filosofía hace parte esencial de un proyecto de educación filosófica. Sobre este encuentro en Chile, véase Colodoro, Foxley y Rossetti (2007). Sobre los proyectos de la UNESCO para promover la educación filosófica a nivel mundial, basta dar una mirada a su página en Internet.

10 Fue Hegel, sin duda, el filósofo que más claramente insistió en la necesidad que tiene para un pueblo, para la conformación de una elevada cultura, la reflexión filosófica. Se lamentaba, en el prefacio a su Ciencia de la lógica, del "asombroso espectáculo de un pueblo culto sin metafísica", al que asemejaba con "un templo con múltiples ornamentaciones, pero sin sanctasanctórum" (Hegel, 1982, p. 36). 
en la enseñanza de la filosofía en la educación media; y, sobre todo, en consolidar un proyecto que lleve a reconocer la importancia de la filosofia en la formación de los niños en la educación básica. Creo que esto hay que tomárselo en serio, pues a veces la filosofía llega demasiado tarde, cuando ya los jóvenes han adquirido hábitos intelectuales y morales que son ajenos a la reflexión serena y profunda que es propia del filosofar. Una filosofía bien trabajada desde los primeros años de la infancia es una herramienta de aprendizaje inigualable.

3. Es necesario consolidar una propuesta donde haya lugar para alternativas diversas y para el desarrollo de la filosofía en espacios no académicos, como una forma de llevar la filosofía a los espacios públicos; y, sobre todo, fomentar la discusión pública basada en buenas razones como el germen esencial a partir del cual crece la sociedad democrática. La filosofía tiene que tomarse las calles y los cafés, los espacios públicos, porque allí hay un lugar para ella y allí ella tiene una función que cumplir. Los griegos inventaron la filosofía, no encerrados en un "pensatorio" (como burlonamente ponía Aristófanes a Sócrates en su comedia Las nubes), sino discutiendo -como lo hacía el propio Sócrates- por las calles y en las plazas y gimnasios de Atenas. No hay que sacar a la filosofía del plano de la discusión pública, de las calles; antes bien, hay que luchar porque esta tenga un lugar significativo en la vida pública en un régimen de vida democrático.

4. Es necesario replantear el proyecto de una pedagogía filosófica a la luz de los desarrollos de los últimos años y teniendo en cuenta que lo importante no es enseñar más filosofía, sino impregnar del espíritu filosófico el aprendizaje de las diversas disciplinas. El desarrollo de las diversas propuestas para hacer filosofía con niños y jóvenes y los nuevos desarrollos de la tecnología, con sus múltiples aplicaciones pedagógicas, ofrecen nuevas luces y oportunidades para el desarrollo de este proyecto.

5. Es preciso articular a través de diversas estrategias las nuevas audiencias filosóficas, así como los nuevos interlocutores filosóficos de los que he hablado antes. ¿Cómo crear un diálogo filosófico auténtico, por ejemplo, entre los niños que trabajan con nosotros en las escuelas, y que hacen filosofía en las escuelas, y sus padres? ¿Cómo articular públicos diversos, interlocutores diversos? Se trata, entonces, de buscar cómo es posible la 
interacción entre los nuevos interlocutores filosóficos (mujeres, niños, jóvenes) y las nuevas prácticas filosóficas surgidas en los últimos tiempos. En ello, sin duda, el uso de medios electrónicos puede ser de gran ayuda.

6. Se debe seguir trabajando en la consolidación de las prácticas extracurriculares en filosofía: grupos de estudio, clubes de pensamiento, coloquios y congresos filosóficos de jóvenes, como una forma de cultivar todos esos nuevos interlocutores filosóficos nacientes. Los adolescentes son absolutamente sensibles a la filosofía y se pueden fascinar muy fácilmente con ella. Los cafés filosóficos abiertos, o las Olimpiadas de Filosofía, ofrecen formatos atractivos para los jóvenes y pueden servir para promover su iniciativa y liderazgo intelectual.

7. Conviene explorar e incorporar las herramientas virtuales en orden a aprovecharlas como un espacio propicio para la reflexión filosófica de los ninos y jóvenes. Se pueden, por ejemplo, buscar alternativas para la educación filosófica en las redes sociales. ¿Cuáles? ¿Cómo garantizar que se dé a través de ellas una efectiva interacción intelectual de carácter crítico y reflexivo? Yo mismo no sabría bien cómo hacerlo, porque no soy muy ducho en el asunto, pero hay allí todo un campo de trabajo para los que nos dedicamos a la enseñanza filosófica.

8. Hay que trabajar en la construcción de proyectos editoriales, en formatos impresos y electrónicos, que den espacio para el desarrollo de nuevas prácticas de escritura filosófica: cuentos, poemas, ensayos, entre otros. Incluso habría que cultivar formas de escribir filosofía que sean distintas a las convencionales, como, por ejemplo, el divertimento filosófico ${ }^{11}$. Se trata, en fin, de imaginar nuevas prácticas de escritura que permitan la creación de una literatura filosófica adaptada a distintas edades y culturas.

9. Hay que propiciar el intercambio y la cooperación internacional en flosofía aprovechando las políticas de la UNESCO o eventos como el Día Mundial de la Filosofía en orden a promocionar el diálogo filosófico

11 Es una idea que he querido desarrollar desde hace cierto tiempo. Se trata de escribir un texto que, siendo filosófico (porque desarrolla una tesis filosófica y refleja una postura filosófica), sea a la vez agradable, e incluso irónico y humorístico. El divertimento filosófico puede ser un espacio muy interesante para la práctica filosófica de los jóvenes y una forma interesante de romper con la solemnidad filosófica, pues permite dar a la filosofía una condición humorística y al humor una densidad filosófica. 
intercultural. Las diversas declaraciones de la UNESCO a favor de la enseñanza de la filosofía son un punto de partida valioso para este diálogo intercultural en filosofía (UNESCO, 2005).

10. Articular todo lo anterior en propuesta pedagógica y política: un proyecto transversal de educación filosófica de carácter intercultural y transdisciplinario. Este último punto reúne todo lo anterior, pues se trata de que todas las sugerencias anteriores se articulen en torno a un único proyecto de amplias dimensiones. Este es un compromiso en el que todos los que hemos dedicado nuestra vida a la enseñanza de la filosofía deberíamos prestar nuestra más esmerada participación.

Unas palabras finales: gran parte de la importancia que concedo a la filosofía en la construcción de una auténtica democracia proviene de haber vivido durante años en un país violento, intolerante y difícil como Colombia. Vivir dicha situación ha reforzado mi convicción de que la filosofía -como opción por la razón y en contra de la violencia- es el único antídoto efectivo que tenemos contra nuestras propias tendencias y el hábito de resolver nuestros conflictos de forma violenta. Creo que, como filósofos y como maestros de filosofía, no podemos prestar un servicio mayor y más importante a la construcción de una democracia seria, de un país tolerante, que el de ser fieles a nuestra vocación de maestros de filosofía y que el amor por la sabiduría es lo que más necesita, y lo que mejor ayuda a construir, una democracia.

Los acuerdos de paz recientemente firmados, y en proceso de implementación, son un punto de partida; pero no más que eso. La época que solemos llamar de "posconflicto" no podrá ser más que una era de nuevos conflictos, ojalá estos más fructíferos y razonables que aquellos en que hemos vivido hasta hoy. Si así fuera, la filosofía tendría un papel cada vez más protagónico, pues la opción por una vida razonable, y la opción por una educación para la razonabilidad, tienen que contar necesariamente con su concurso. La paz se construye solamente en la medida en que luchamos contra toda forma de injusticia, propiciamos las condiciones en que es posible decir la verdad despojados de miedo y nos esforzamos por hacer guiar nuestra vida personal y social por la búsqueda incesante de la sabiduría. 
Ceppas, F. (2004): Sobre as práticas filosóficas extra acadêmicas. En Kohan (Org.), Filosofia. Caminhos para seu ensino (pp. 155-167). Rio de Janeiro: DP\&A.

Colodoro, M., Foxley, A. M. \& Rossetti, C. (2007). Palabra de filósofo. Jornadas de reflexión en el Día Mundial de la Filosofia. Santiago de Chile: Comisión Nacional Chilena de Cooperación con UNESCO.

Comenio, J. A. (1998). Didáctica Magna. México: Porrúa.

Daniel, M-F. et al. (1997). Ideas y textos para pensar filosóficamente la matemática en la escuela primaria. En Kohan \& Waksman (Comps.) ¿Quées filosofía para niños? Ideas y propuestas para pensar la educación (pp. 109-128). Buenos Aires: Universidad de Buenos Aires.

Dewey, J. (1982 [1917]): The Need for a Recovery of Philosophy. En Boydston (Ed.), The Middle Works of John Dewey (Vol. 10) (pp. 3-48). Carbondale: Southern Illinois University Press.

Dewey, J. (1977 [1918]). Philosophy and Democracy. En Boydston (Ed.), The Middle Works of John Dewey (Vol. 11) (pp. 41-53). Carbondale: Southern Illinois University Press.

Dewey, J. (2017). La democracia como forma de vida. (Trad. D. A. Pineda R.). Bogotá: Editorial Pontificia Universidad Javeriana. (En prensa)

Gaarder, J. (1995). El mundo de Sofia. Bogotá: Norma-Siruela.

Hegel, G. W. F. (1982). Ciencia de la lógica. Buenos Aires: Ediciones Solar.

Lipman, M. (2001). La dramatización de la filosofía. Utopía y Praxis Latinoamericana. Revista Internacional de Filosofía Iberoamericana y Teoría Social, 6(14), 94-100.

Marx, K. (1938). Obras escogidas (Trad. W. Roces). Barcelona: Ediciones Europa-América.

Nussbaum, M. (1995). Introducción: forma y contenido, filosofía y literatura. Estudios de Filosofia, 11, 43-105.

Obiols, G. (2002). Uma introdução ao Ensino da Filosofia. Ijuí: Editorial Unijui. Phillips, C. (2002). Sócrates Café. Un soplo fresco de filosofia. Madrid: Ediciones Temas de Hoy. 
Pineda, D. (2001). Sobre enseñar y aprender en filosofía. Universitas Philosophica, 18(37), 129-144.

Pineda, D. (2004a). ¿En qué consiste una educación filosófica? En Vargas \& Cárdenas(Eds.), Filosofia, pedagogía y enseñanza de la filosofia (pp. 125-161). Bogotá: Universidad Pedagógica Nacional.

Pineda, D. (2004b). Literatura e educação filosófica. En Kohan (Org.) Lugares da Infancia: Filosofia (pp. 71-96). Rio de Janeiro: DP\&A.

Pineda, D. (2008a). La enseñabilidad de la filosofía: la perspectiva de la 'traducción. En Valera-Villegas, Madriz \& Carpio (Comps.) La filosofia como experiencia del pensar. Enseñanza de la filosofía y filosofía paralentre niños. Caracas: Centro de Investigaciones Posdoctorales de la Universidad Central de Venezuela-Consejo de Desarrollo Científico Humanístico y Tecnológico de la Universidad Nacional Experimental Simón Rodríguez.

Pineda, D. (2008b). Algunas hipótesis de trabajo (construidas en clave autobiográfica) sobre una educación científica en perspectiva filosófica. En Giraldo \& Berdugo(Comps.), Talento, inventiva y creatividad. Arte y ciencia con conciencia (pp. 118-142). Bogotá: Bunaima.

Pineda, D. (2012). Hegel: sobre la enseñanza de la filosofía. Universitas Philosophica, 29(59), 139-159.

Rancière, J. (2007). El odio a la democracia. Buenos Aires: Amorrortu.

Rorty, R. (1986). La primacía de la democracia frente la filosofía. Sociológica, 2(3), 105-128.

Salazar Bondy, A. (1967). Didáctica de la filosofía. Lima: Editorial Arica.

UNESCO. (2005). Informe del director general relativo a una estrategia intersectorial sobre la filosofía (Documento del Consejo Ejecutivo de la Organización de las Naciones Unidas para la Educación, la Ciencia y la Cultura No. $171 \mathrm{EX} / 12$ ). Recuperado del sitio web de la UNESCO: http://unesdoc. unesco.org/images/0013/001386/138673s.pdf

Voltaire. (2006). Cuentos completos en prosa y verso. México: Fondo de Cultura Económica-Siruela.

Zuleta, E. (1995). Educación y democracia. Un campo de combate. Bogotá: Corporación Tercer Milenio-Fundación Estanislao Zuleta. 